\title{
Removal of silicone oil droplets adhering to the posterior surface of an intraocular lens (IOL)
}

This article was published in the following Dove Press journal: International Medical Case Reports Journal

\section{Chih-Ling $\mathrm{Hu}$ \\ Kai-Ling Peng}

Department of Ophthalmology, Chi Mei Medical Center, Tainan, Taiwan
Correspondence: Kai-Ling Peng Department of Ophthalmology, Chi Mei Medical Center, No.90I, Zhonghua Road, Yongkang Dist, Tainan City 710, Taiwan Tel +886 628I 28I I ext 57247 Email caropk165@gmail.com
Purpose: We report a rare case of silicone oil droplets adhering to the posterior surface of an intraocular lens (IOL) after removal of silicone oil for a patient with retinal reattachment, who had a history of pseudophakic rhegmatogenous retinal detachment.

Case report: A 45-year-old male with a history of cataract surgeries of both eyes developed pseudophakic retinal detachment in his left eye. He received surgeries of scleral buckle and standard 3-port pars plana vitrectomy with silicon oil tamponade. With retinal attachment for 7 months, he underwent removal of silicone oil in the left eye. However, a big silicone oil droplet was found on the posterior surface of the IOL with complaints of distorted micropsia and poor vision, a month later. Pars plana vitrectomy using a 20-gauge vitreous cutter, which was supposed to have a higher cleaning capability compared with a smaller size device, was performed to aspirate the main part of the big oil droplet. The residual dispersed smaller droplets at the center of the visual axis were swept peripherally using a 27 -gauge bending tip cannula. Fortunately, the patient regained his vision of 20/20 without distortion and micropsia in his left eye. Conclusion: This was a rare case where silicone oil droplets were found adhering to the posterior surface of an IOL after removing silicone oil a month later. We used a 20-gauge vitrectomy system to remove large oil droplets and swept smaller ones off the visual axis to improve the vision and visual quality.

Keywords: silicone oil droplet, silicone intraocular lens, retinal detachment, retinal reattachment, 20-gauge vitreous cutter, 27-gauge bending tip cannula

\section{Introduction}

The adhesion of silicone oil droplets to an intraocular lens (IOL) may potentially occur in pseudophakic patients with silicone oil tamponade for previous vitreoretinal surgery after removal of silicone oil under stable condition of the well-attached retina. ${ }^{1}$ It is well documented that silicone oil may interplay with various IOL biomaterials, especially the silicone lenses, which were proved to have maximal interaction with silicone oil. ${ }^{2}$ Apple et al have speculated that the more hydrophobic a lens biomaterial is, the more adherent it is to silicone oil, which is also hydrophobic. ${ }^{2}$

This clinical complication may result in significant visual disturbance, such as decreasing visual acuity, visual distortion, and micropsia because of the convex posterior surface of silicone oil droplets at the visual axis on either side of adherence to the IOL. The central part of convex curvature minimizes the images and the marginal part distorts vision and produces glare due to the adherence of silicone oil droplets at the visual axis on the posterior side of the IOL. 
We report a rare case of silicone oil droplets adhering to the posterior surface of an IOL after removal of silicone oil for a patient with retinal reattachment, who had a history of pseudophakic rhegmatogenous retinal detachment.

\section{Case report}

A 45-year-old man with a history of myopia and had received cataract surgeries in both eyes at a local eye clinic 6 years ago without information of IOL material. After that, he had undergone focal photocoagulation in his left eye for a retinal break.

He suffered from a sudden onset of floaters with progressive visual field defect in his left eye for 4 days before he visited our hospital. He was referred from a local eye clinic where retinal detachment in his left eye was diagnosed. Under slit lamp examination, the 3-piece posterior chamber IOLs were in capsular bags in both eyes under status of post neodymium:YAG laser posterior capsulotomy. Indirect ophthalmoscopy showed bullous retinal detachment over the inferior area with foveal involvement in his left eye. An encircling scleral buckle and a standard 20-gauge 3-port pars plana vitrectomy with silicone oil instillation was performed successfully.

With retinal attachment for 7 months, he underwent removal of silicone oil in the left eye. However, an ovalshaped silicone oil droplet was found on the posterior surface of the IOL in the visual axis with complaints of distorted micropsia and poor vision a month later (Figure 1). His vision then decreased to 3/20 in his left eye. The refraction could not be measured by automatic refractometry. Another pars plana

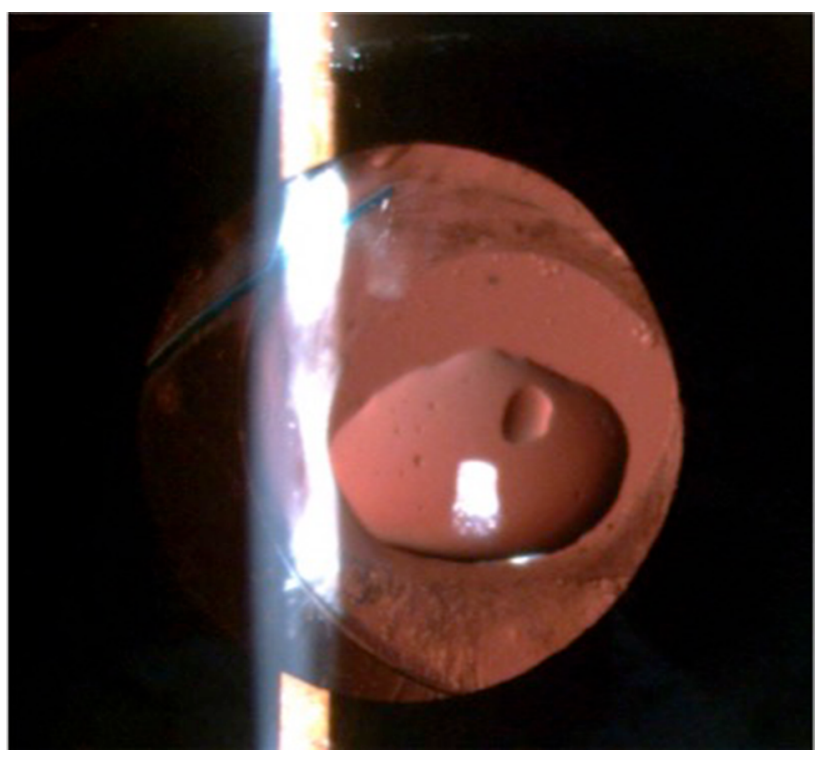

Figure I An oval-shaped silicone oil droplet was found on the posterior surface of the intraocular lens in the visual axis. vitrectomy of a 20-gauge system (Alcon Accurus 400VS surgical system) was performed. A 20-gauge infusion cannula was placed in the inferotemporal site, and a 20 -gauge vitreous cutter was passed through the superonasal site. The largest silicone oil droplet was aspirated with a higher aspiration setting of $300 \mathrm{mmHg}$ as the opening of vitrector was totally buried inside the silicone oil droplets. The residual smaller ones at the center of the visual axis were swept peripherally by a 27-gauge bending tip cannula (Figure 2).

After the silicone oil was removed, the surface of the IOL was clear in the visual axis. The patient's visual acuity returned to 20/20 without distortion and micropsia.

\section{Discussion}

Because of the similar chemical structures of silicone oil molecules and silicone IOL surface, they are attracted towards each other and adhere firmly, which leads to a large contact area between the oil droplets and the surface of the IOL. Sometimes, the silicone oil may slowly diffuse into the silicone IOL. ${ }^{2}$ Instead of finding the adherence of silicone oil droplets to the posterior surface of the IOL, while removing silicone oil in the vitreous cavity, like most of the cases reported previously, we found it a month later after removing the silicone oil. Maybe the residual floating silicone oil droplets in the vitreous cavity were attracted to the IOL posterior surface especially under supine position, resulting in an extremely short distance between each other and further stuck together due to the same hydrophic character.

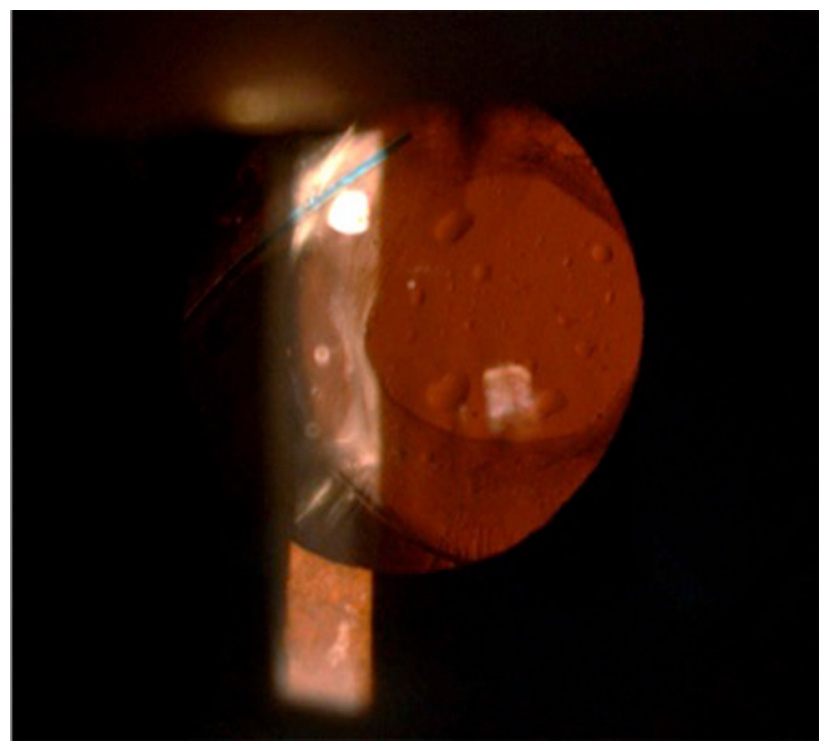

Figure 2 The largest silicone oil droplet was aspirated by 20 -gauge vitrector and the residual smaller ones were swept peripherally by a 27 -gauge bending tip cannula. 
Various methods were studied to remove silicone oil droplets that stick to the surface of the silicone IOL. ${ }^{1,2}$ IOL exchange is a radical but complicated treatment; therefore, it should be the last choice. Horgan and Cooling reported using a Simcoe style cannula to wipe off oil droplets. ${ }^{3}$ Mein applied a viscoelastic substance to the IOL's posterior surface to facilitate clearing. ${ }^{4}$ Kageyama and Yaguchi only used a lens hook to scrape away the oil droplets. ${ }^{5}$ Perfluorohexyloctane has also been used to dissolve silicone oil from IOLs. ${ }^{6}$ Using a 25 -gauge transconjunctival vitrectomy system to remove the silicone oil was also reported. ${ }^{7}$ To break the viscosity between silicone oil droplets and the IOL, a 20-gauge vitrector with a large orifice and a higher aspiration setting was used in our case. Making sure that the orifice was buried completely inside the largest silicone oil droplets instead of aspirating from a distance was the key point. The residual smaller ones, which could not be aspirated by the vitrector, were swept off the visual axis using a 27 -gauge bending tip cannula. Removing the adhering silicon oil droplets from IOLs in this way seemed to be a simple and safe method to restore the patient's vision.

\section{Ethics statement}

Written informed consent was obtained from the patient for publication of this Case Report and accompanying images.

\section{Author contributions}

C-LH carried out drafting of the manuscript. K-LP was responsible for the clinical management of the patient, the design of the case report, and revision. Both authors contributed toward data analysis, drafting and revising the paper and agree to be accountable for all aspects of the work. Both the authors read and approved the final manuscript.

\section{Disclosure}

The authors report no conflicts of interest in this work.

\section{References}

1. Apple DJ, Federman JL, Krolicki TJ, et al. Irreversible silicone oil adhesion to silicone intraocular lenses. A clinicopathologic analysis. Ophthalmology. 1996;103(10):1555-1562.

2. Apple DJ, Isaacs RT, Kent DG, et al. Silicone oil adhesion to intraocular lenses: an experimental study comparing various biomaterials. J Cataract Refract Surg. 1997;23(4):536-544.

3. Horgan SE, Cooling RJ. Irreversible silicone oil adhesion. Ophthalmology. 1997;104(6):898-900.

4. Mein CE. Posterior surface condensation on silicone IOLs. Ophthalmology. 1995;102(10):1412-1413.

5. Kageyama T, Yaguchi S. Removing silicone oil droplets from the posterior surface of silicone intraocular lenses. J Cataract Refract Surg. 2000;26(7):957-959.

6. Zeana D, Schrage N, Kirchhof B, Wenzel M. Silicone oil removal from a silicone intraocular lens with perfluorohexyloctane. J Cataract Refract Surg. 2000;26(2):301-302.

7. Sakimoto S, Tsukamoto Y, Saito Y. Removal of silicone oil droplet adhering to a silicone intraocular lens using 25-gauge instrumentation. J Cataract Refract Surg. 2009;35(2):383-385.
International Medical Case Reports Journal

\section{Publish your work in this journal}

The International Medical Case Reports Journal is an international, peer-reviewed open-access journal publishing original case reports from all medical specialties. Previously unpublished medical posters are also accepted relating to any area of clinical or preclinical science. Submissions should not normally exceed 2,000 words or

\section{Dovepress}

4 published pages including figures, diagrams and references. The manuscript management system is completely online and includes a very quick and fair peer-review system, which is all easy to use. Visit http://www.dovepress.com/testimonials.php to read real quotes from published authors. 